Military Technical College

Kobry El-Kobba

Cairo, Egypt

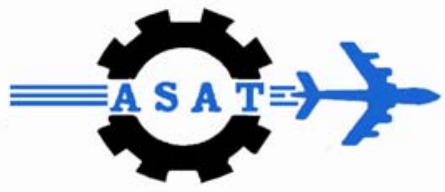

12-th International Conference

on

Aerospace Sciences \&

Aviation Technology

\title{
CORRELATION BETWEEN MICROSTRUCTURE AND FATIGUE PROPERTY OF TI-6AL-4V ALLOY USED IN AEROSPACE APPLICATIONS
}

\author{
Ibrahim $^{*}$ K.M., Mueller ${ }^{* *}$ J. and Wagner ${ }^{* *}$ L.
}

\begin{abstract}
Ti-6Al-4V is one of the most commonly used titanium alloys in the aviation industry due to its high strength-to-weight ratio, high operating temperature, and corrosion resistance. In this study, two batches of Ti-6.3Al-4.17V samples were subjected to different thermomechanical processes. The first batch was treated below the $\beta$-transus temperature $\left(980{ }^{\circ} \mathrm{C}\right)$ to get duplex structure $(\alpha+\beta)$, while the second batch was treated above $\beta$-transus temperature $\left(1050{ }^{\circ} \mathrm{C}\right)$ to get lamellar structure. Rotating bending fatigue test was carried out using electropolishing surface condition. It is observed that the treatment above $\beta$-transus showed higher fatigue limit than the samples treated below the $\beta$-transus. This is attributed to the fine structure (lamellar structure) obtained at $1050{ }^{\circ} \mathrm{C}$ than the duplex structure $(\alpha+\beta)$ obtained at $980^{\circ} \mathrm{C}$. In addition, the fatigue crack initiation sites existing in the structures were determined.
\end{abstract}

KEYWORDS: Ti-6Al-4V, $\beta$-transus, fatigue property, electropolishing, fatigue crack initiation site, thermomechnaical treatment.

\section{INTRODUCTION}

Ti-6Al-4V alloy has widely been used in the non-aerospace as well as aerospace applications. The majority of Ti-forgings for aircraft are covered by Ti-6Al-4V and, therefore this alloy certainly belongs to the most investigated Ti-alloys[1,2]. Furthermore, the performance of Ti-6Al-4V is considered as one of the most popular $\alpha-\beta$ titanium alloys, in which it probably satisfies requirements for some automotive parts such as connecting rods[3,4]. In addition, the titanium alloy Ti-6Al-4V is used also for biomedical applications, in general for parts of total hip joint replacement and in particular for femoral stem[5,6]. These applications call primarily for adequate high cycle fatigue strength. The study of fatigue crack initiation and growth of such titanium alloys has received considerable interest because of their extensive use in aerospace and other industrial applications[7]. Understanding the crack growth behaviour of these alloys, however, is complicated by the changes in the microstructures that occur by even small

*Researcher, Manufacturing Technology Dept., CMRDI, Cairo, Egypt. (khaledabouelela@yahoo.com)

${ }^{* *}$ Graduate student, Materials science and Engineering Dept., TU-Clausthal, Germany.

${ }^{* * *}$ Professor, Materials science and Engineering Dept., TU-Clausthal, Germany. 
changes in heat treatment which in turn result in changes in their flow properties and their sensitivity to external environments[8]. It is well known that the resistance to crack initiation under cyclic loading is one of the critical design parameter for several applications in automotive and aerospace industries. The way the first defects appear must be studied at the scale of microstructure in order to understand and to avoid any damage during service. It is well documented that fatigue crack initiation is strongly influenced by several characteristics of the microstructure like grain size, grain orientation and mis-orientation of the grain[9]. The present study aims to find a correlation between microstructure feature of Ti-6.3Al-4.17V and fatigue crack initiation sites as well as fatigue crack growth in the structure.

\section{EXPERIMENTAL WORK}

Ti-6.3Al-4.17V was first cast in vacuum induction furnace as rods with a diameter of 50 $\mathrm{mm}$. Hot swaging technique was used to reduce the cross section diameter into $10 \mathrm{~mm}$ in 9 steps using different dies. The final chemical composition is shown in Table 1. The rods were divided into two batches for applying two different solution treatments. The thermomechanical process was carried out in this work is schematically shown in Fig. 1. The first batch was treated just below $\beta$-transus temperature $\left(980{ }^{\circ} \mathrm{C}\right)$ to get duplex structure $(\beta+\alpha$ structure). While the second batch was treated above the $\beta$-transus temperature $\left(1050^{\circ} \mathrm{C}\right)$ to get lamellar structure. In both cases, the quenching media was changed (water or air) to get different cooling rates. Rotating fatigue test was carried out using round samples with the dimensions shown in Fig. 2. The fatigue tests were performed at $50 \mathrm{~Hz}$ frequency in laboratory air condition. The specimens were electropolished before testing. Fatigue crack nucleation sites were located using optical and scanning electron microscopes.

\section{RESULTS AND DISCUSSION}

\section{Microstructure}

Generally, the mechanical properties of Ti-6Al-4V are mainly depended on the refinement of the grains upon cooling from $\beta$-region, or $\alpha-\beta$ region and subsequent lowtemperature aging to decompose martensite formed upon quenching. In this study the solution treatment was done in two different temperatures, whereas the first one was applied above $\beta$-transus of $1050^{\circ} \mathrm{C}$ to produce lamellar structure, as shown in Fig. 3 a,b. The second treatment was carried out just below the $\beta$-transus of $980{ }^{\circ} \mathrm{C}$ to produce bimodal or duplex structure, as shown in Fig. $3 \mathrm{c}, \mathrm{d}$. In each case, quenching cooling rate was changed from low cooling rate by using air-cooling to high cooling rate by using water quenching. This change in cooling rate has a direct influence on the fines of the grains either in the lamellar or duplex structure. As shown in Fig. 3 b, the lamellar structure has a width of about $1 \mu \mathrm{m}$ and approximately $1 \mathrm{~mm}$ long. While in case of aircooling, the lamellar structure is coarser, in which it has a width of about 2-3 $\mu \mathrm{m}$ and 550 $\mu \mathrm{m}$ long, Fig. 3 a. The same effect was noticed for the duplex structure, where the water 
quenched samples obtained finer structure than the air-cooled ones, as shown in Fig. 3 $\mathrm{c}, \mathrm{d}$. It is also observed that the lamellar width in duplex structure has approximately the same size as the lamellar that has been got by treatment above the $\beta$-transus. It is also noticed that the duplex structure has $\alpha$ volume fraction of about $20 \%$ with a diameter of approximately $10-15 \mu \mathrm{m}$.

\section{Mechanical properties}

The results of tensile tests at room temperature are shown in Table 2 for both lamellar and duplex structures. As expected, the lamellar structure has relatively lower yield and ultimate strengths than the duplex structure due to the existence of $\alpha$-particles as a foreigner phase in $\beta$-matrix. Also, the water quenched samples showed higher strength than the air-cooled ones either in lamellar or duplex structure due to the finer structure obtained in case of water quenching condition. This is in agreement with the Hall-Pitch relationship, in which the yield strength increases with decreasing the grain size. At the same time, the lamellar width, colony size and a volume fraction, and size have a big role in determining the strength of the studied Ti-6.3Al-4.17V alloy. Therefore, the maximum ultimate strength of $1110 \mathrm{MPa}$ was obtained for the water quenched samples with the finest structure compared to the other ones.

The rotating bending fatigue of the studied Ti-6.3Al-4.17V alloy in the four different conditions has been determined. The S-N curves of lamellar and duplex structures are shown in Fig. 4 a,b. It is obvious that all microstructural parameters which increase the yield strength will have a tendency to increase the fatigue strength of the investigated alloy as well. This was clear for the water quenched samples compared to the air-cooled ones due to the refined microstructure obtained in water quenching condition. On the other hand, the lamellar structure showed higher fatigue limit than the duplex structure. For example, the water quenched samples with lamellar structure obtained a fatigue limit of $620 \mathrm{MPa}$ compared to $490 \mathrm{MPa}$ for the water quenched duplex structure.

In addition, the reduction of prior $\beta$ grain size of lamellar structure will increase the fatigue strength, as shown in Fig. 4 a. Also, the reduction of primary a volume fraction in duplex structure will increase the fatigue strength, Fig. $4 \mathrm{~b}$. Therefore, the water quenched samples with fine lamellar structure obtained higher fatigue limit (620 MPa) than the air-cooled one (500 MPa). At the same time, water quenched samples with duplex structure showed relatively higher fatigue limit (490 MPa) than the air-cooled ones (480 MPa) due to the existence of relatively some $\alpha$-clusters in the structure.

The fatigue crack initiation sites in duplex structure have been thoroughly studied. It is noticed that the fatigue crack started from $\alpha$-particle and goes through the $\beta$-matrix to connect another $\alpha$-particle and finally stops at $\alpha$-particle, as shown in Fig. 5 . Thereby, these primary a-particles can act as sites for crack initiation which in turn the 
microcracks can propagate through. Figure 6 illustrates an example with high magnification for a fatigue crack initiation site. It is seemed that the crack initiates at the interface between the two phases $\alpha$ and $\beta$, as shown for the $\alpha$-particles (A\&B). However, the propagation does not necessarily follow these interfaces. But, it could be suggested that the crack can start from non-uniform (or triple edge) a-particle $(A)$ and stop at relatively rounded $\alpha$-particle $(B)[10,11]$.

The fracture surface of the fatigue samples for both lamellar and duplex structures has been also studied. It is seemed that fatigue crack initiation site on both cases (lamellar and duplex structure) always occurs on the sample surface[12], as shown in Fig. 7 a,b. The fracture surfaces of lamellar structure as well as duplex structure are investigated in details, as shown in Fig. 8 a,b. As shown in Fig. 8 a, the fracture surface of the lamellar structure showed a quasi-cleavage fracture due to the existence of $\beta$-matrix and also hard $\alpha$-phase at the grain boundaries. While, the duplex structure showed cleavage fracture with low amount of ductile fracture in addition to existing of some micro-cracks on the fracture surface[13], Fig. $8 \mathrm{~b}$. It is suggested that these cracks could link the $\alpha-$ particles existing in the $\beta$-matrix. This investigation on the fracture surface was in agreement with the fatigue results obtained in this study, whereas the cleavage fracture of duplex structure is related to its low fatigue limit value and the quasi-cleavage fracture of the lamellar structure is linked to its high fatigue limit.

\section{CONCLUSIONS}

1. Hot swaging of Ti-6.3Al-4.17V followed by solution treatment above $\beta$-transus at $1050{ }^{\circ} \mathrm{C}$ obtained fine lamellar structure by using water quenching and coarser structure by using air-cooling.

2. Hot swaging of Ti-6.3Al-4.17V followed by solution treatment just below $\beta$-transus at $980{ }^{\circ} \mathrm{C}$ obtained fine duplex structure with $20 \%$ a-phase by using water quenching and coarser structure with air-cooling condition.

3. Water quenched samples for both lamellar and duplex structures showed higher tensile properties than the air-cooled samples.

4. Maximum fatigue strength of about $620 \mathrm{MPa}$ was obtained for the water quenched samples with lamellar structure, while the minimum value of $480 \mathrm{MPa}$ was obtained for the air-cooled samples with duplex structure.

5. In both lamellar and duplex structures, the fatigue crack initiation site always occurs on the electropolished samples surface.

6. In duplex structure, fatigue crack initiates at the interface between the two phases $\alpha$ and $\beta$ and the propagation does not necessarily follow these interfaces. 
7. The fracture surface of lamellar structure obtained quasi-cleavage fracture mode, while the duplex structure showed cleavage fracture with low amount of ductile fracture and micro-cracks on the fracture surface.

\section{ACKNOWLEDGEMENTS}

This work has been done at the institute of Materials Science and Engineering of TU-Clausthal, Germany, in which DAAD agency supported a part of this work.

\section{REFERENCES}

[1] W. Horvath, W. Marketz and E. Gach, Proceeding of the $10^{\text {th }}$ World Conference on Titanium, (2003), Germany, p. 2713.

[2] Y. Kossaka, J.C. Fanning and S.P. Fox, Proceeding of the $10^{\text {th }}$ World Conference on Titanium, (2003), Germany, p. 3027.

[3] S. Kojima and H. Oyama, Proceeding of the $10^{\text {th }}$ World Conference on Titanium, (2003), Germany, p. 3089.

[4] Y.Q. Zhao, Y.L. Li, H. Wu, C.L. Liu, L. Feng and K.Y. Zhu, Proceeding of the $10^{\text {th }}$ World Conference on Titanium, (2003), Germany, p. 3083.

[5] D.F. Williams, "Titanium for medical applications, Titanium in medicine", Edited by D.M. Brunette et al., Springer-Verlag Berlin Heidelberg, Germany, (2001).

[6] M. Windler and R. Klabunde, "Titanium for hipand knee protheses, Titanium in medicine", Edited D.M. Brunette et al., Springer-Verlag Berlin Heidelberg, Germany, (2001).

[7] K. Sadananda and A.K. Vasudevan, International Journal of Fatigue, vol. 27, (2005), p. 1255.

[8] T. Goswami, Materials Design, vol. 24, (2003), p. 423.

[9] F. Sansoz and H. Ghonem, Metallurgical and Materials Transactions A, vol. 34 A, (2003), p. 2566.

[10] B.Y. Kokuoz, Y. Kosaka and H.J. Rack, "High cycle fatigue crack initiation and growth in TIMETAL ACB", Journal of Materials Engineering and Performance, vol. 14, No. 6, 2005, p.773.

[11] R.O. Ritchie, B.L. Boyce, and W.W. Milligan, Thresholds for high cycle fatigue in a turbine engine Ti-6Al-4V alloy", International Journal of Fatigue, vol. 21, 1999, p. 653.

[12] M. Kocan, B.Y. Kokuoz, H.J. Rack and L. Wagner, "The high cycle fatigue performance of lightweight titanium automotive suspensions", JOM, Nov. 2005, p. 66.

[13] C.J. Boehlert, C.J. Cowen and D.B. Miracle, "In situ scanning electron microscopy observations of tensile deformation in a boron modified Ti-6Al-4V alloy", Scripta Materialia, vol. 55, 2006, p. 465. 
Table 1. Chemical composition of the investigated titanium alloy (Ti-6.3Al-4.17 V)

\begin{tabular}{|l|c|c|c|c|c|c|c|c|}
\hline Alloy & Al & $\mathbf{V}$ & Mo & Fe & Si & $\mathbf{O}$ & $\mathbf{N}$ & Ti \\
\hline Ti-6Al-4V & 6.3 & 4.17 & 0.03 & 0.19 & 0.02 & 0.14 & 0.013 & Rest \\
\hline
\end{tabular}

Table 2. Tensile properties of the investigated Ti-6AI-4V alloy

\begin{tabular}{|c|c|c|c|c|}
\hline Sample No. & $\begin{array}{c}E \\
{[\mathrm{GPa}]}\end{array}$ & $\begin{array}{c}\sigma_{0.2 \%} \\
{[\mathrm{MPa}]}\end{array}$ & $\begin{array}{c}\sigma_{\mathrm{u}} \\
{[\mathrm{MPa}]}\end{array}$ & $\begin{array}{c}\text { Elongation } \\
\text { [\%] }\end{array}$ \\
\hline $1050^{\circ} \mathrm{C} /$ air-cooled & 117 & 955 & 1109 & 6.1 \\
\hline $1050^{\circ} \mathrm{C} /$ water quenched & 117 & 1054 & 1022 & 3.1 \\
\hline $980^{\circ} \mathrm{C} /$ air-cooled & 114 & 972 & 1046 & 13.1 \\
\hline $980^{\circ} \mathrm{C} /$ water quenched & 115 & 1062 & 1110 & 13.2 \\
\hline
\end{tabular}

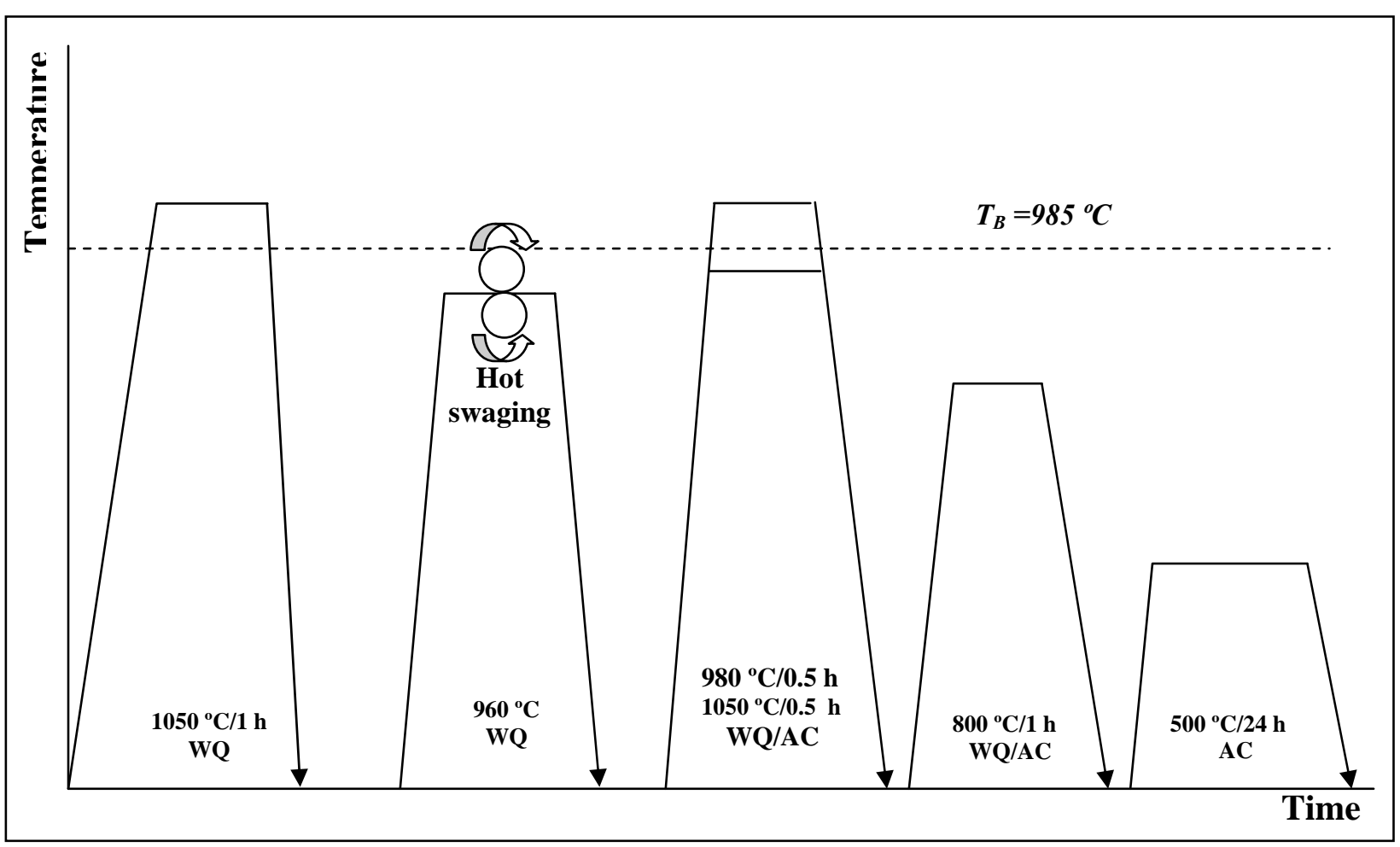

Fig. 1. Thermomechanical process for producing Ti-6.3Al-4.17V samples 


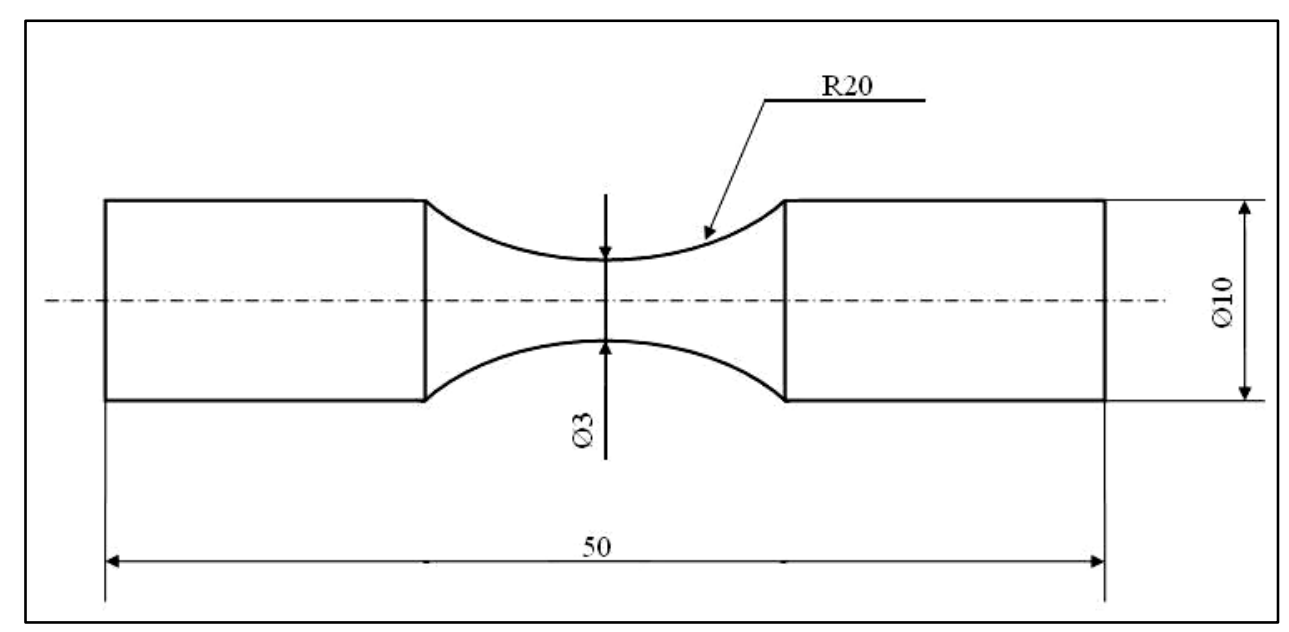

Fig. 2. Schematic drawing of the fatigue sample
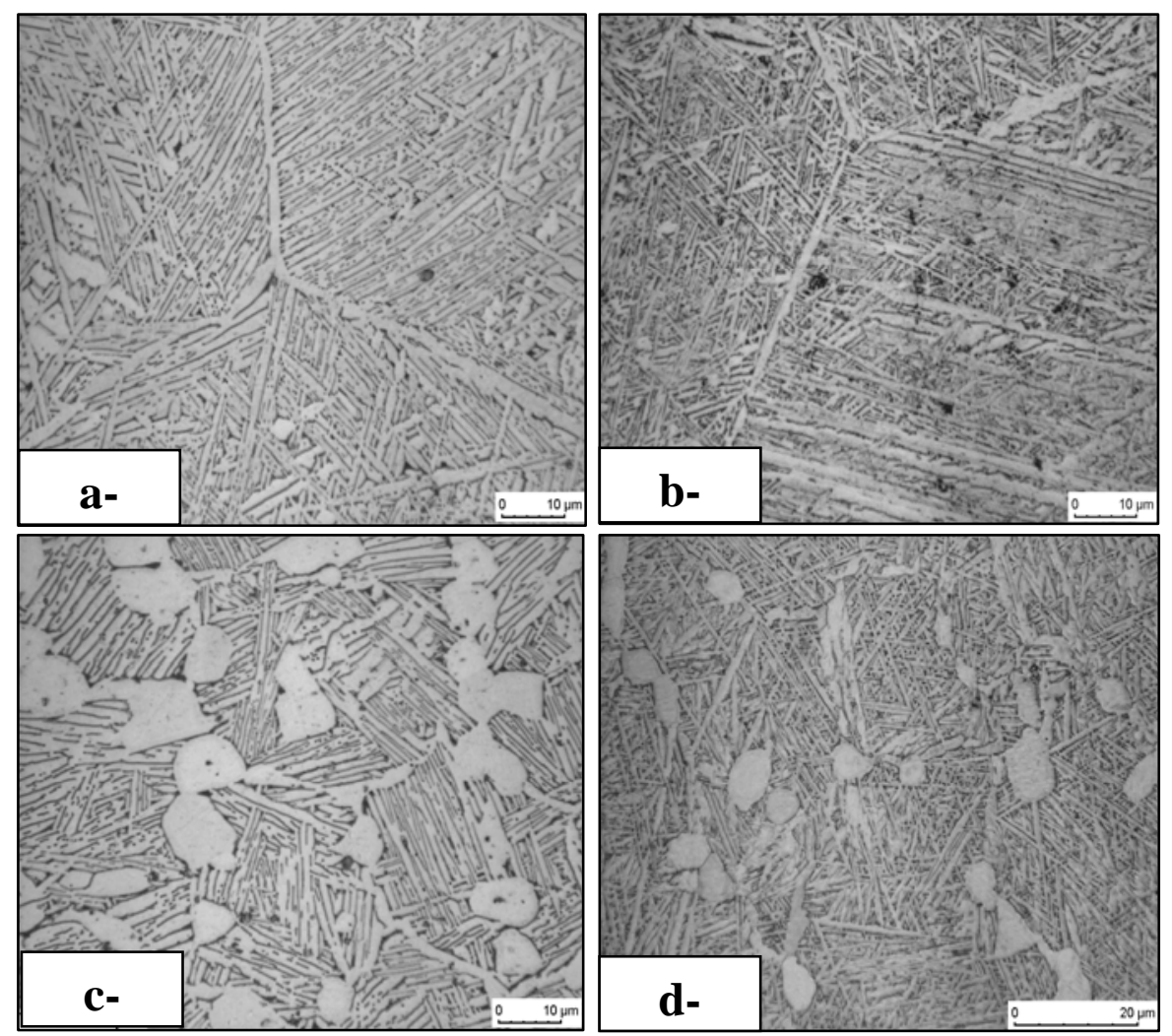

Fig. 3. Schematic drawing of the fatigue sample 

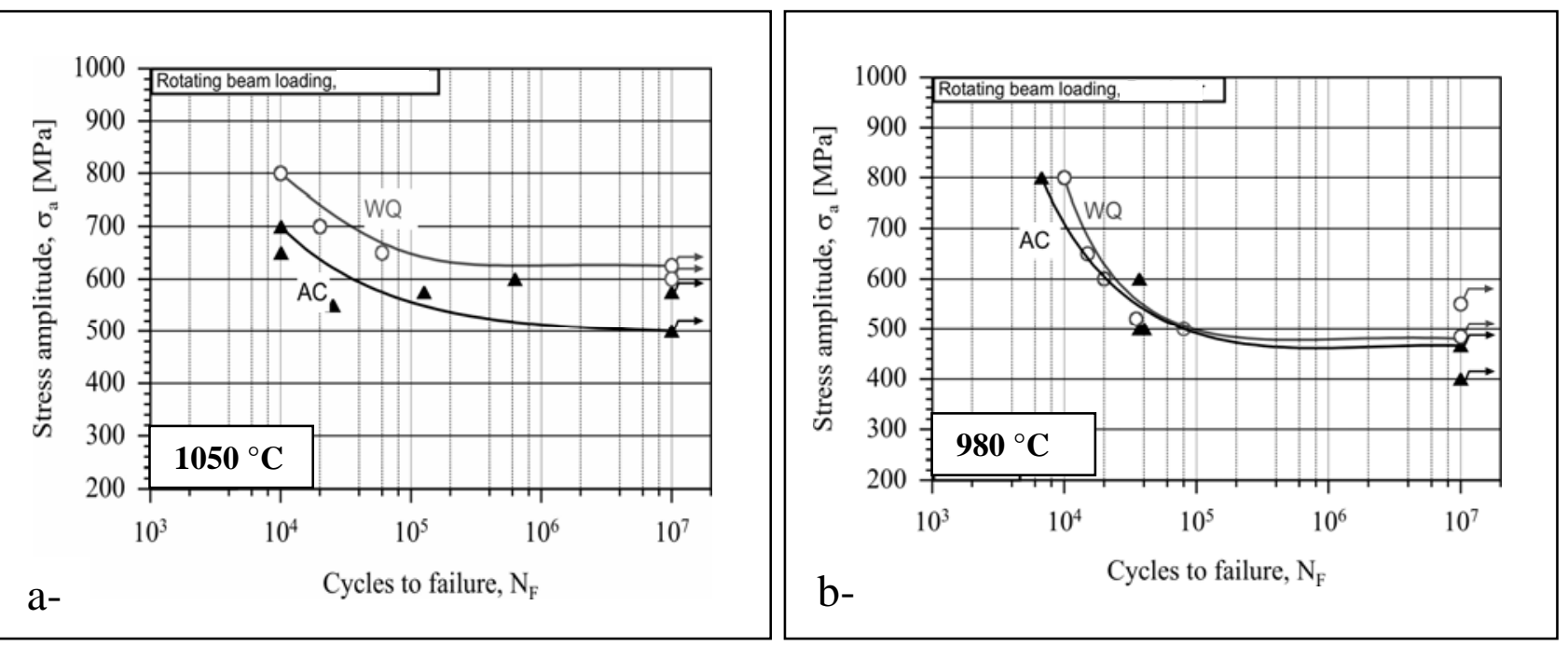

Fig. 4. S-N curves of the investigated Ti-6.3Al-4.17V alloy a- Lamellar structure, b- Duplex structure
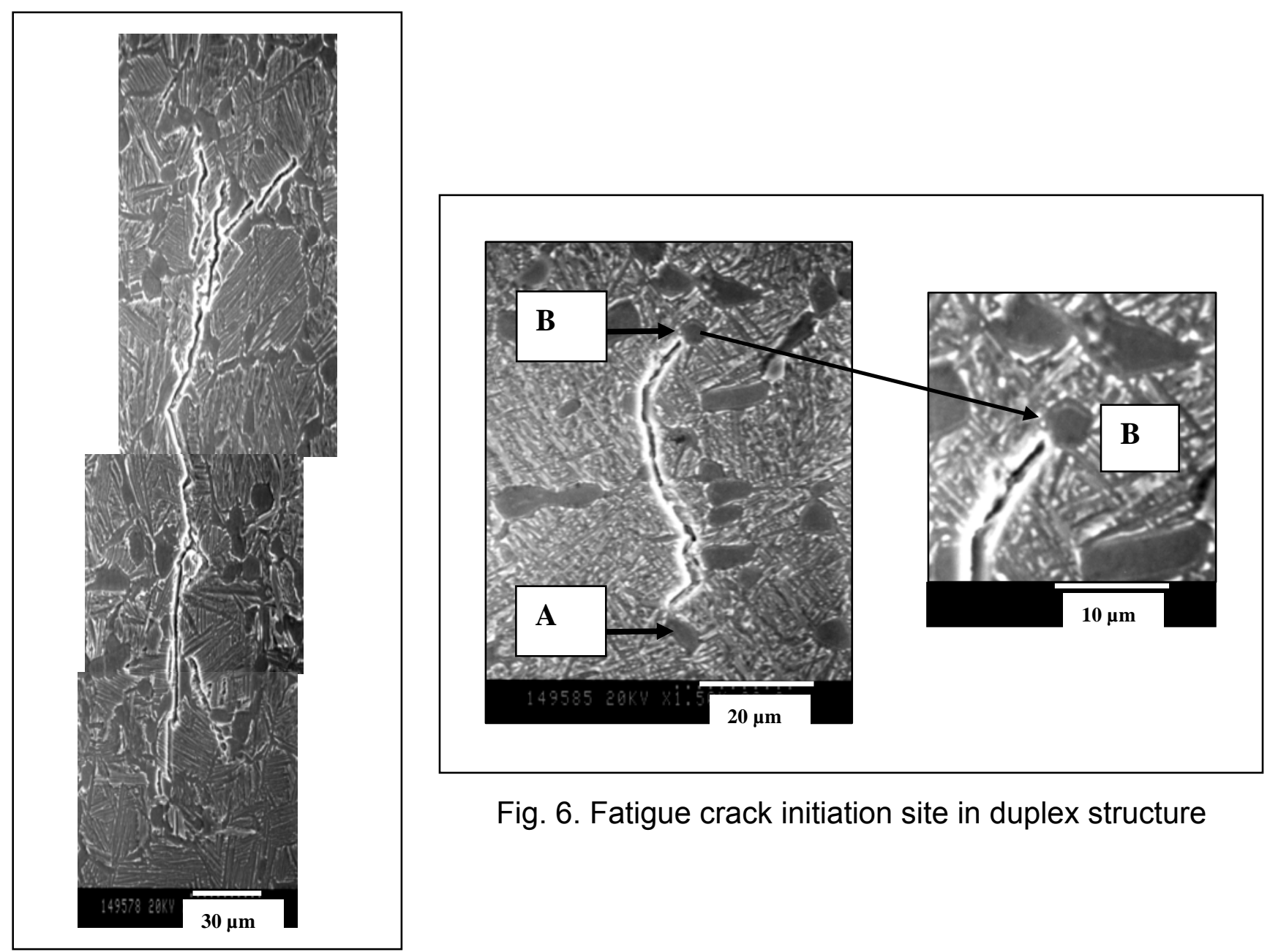

Fig. 6. Fatigue crack initiation site in duplex structure

Fig. 5. Fatigue crack propagation in duplex structure 

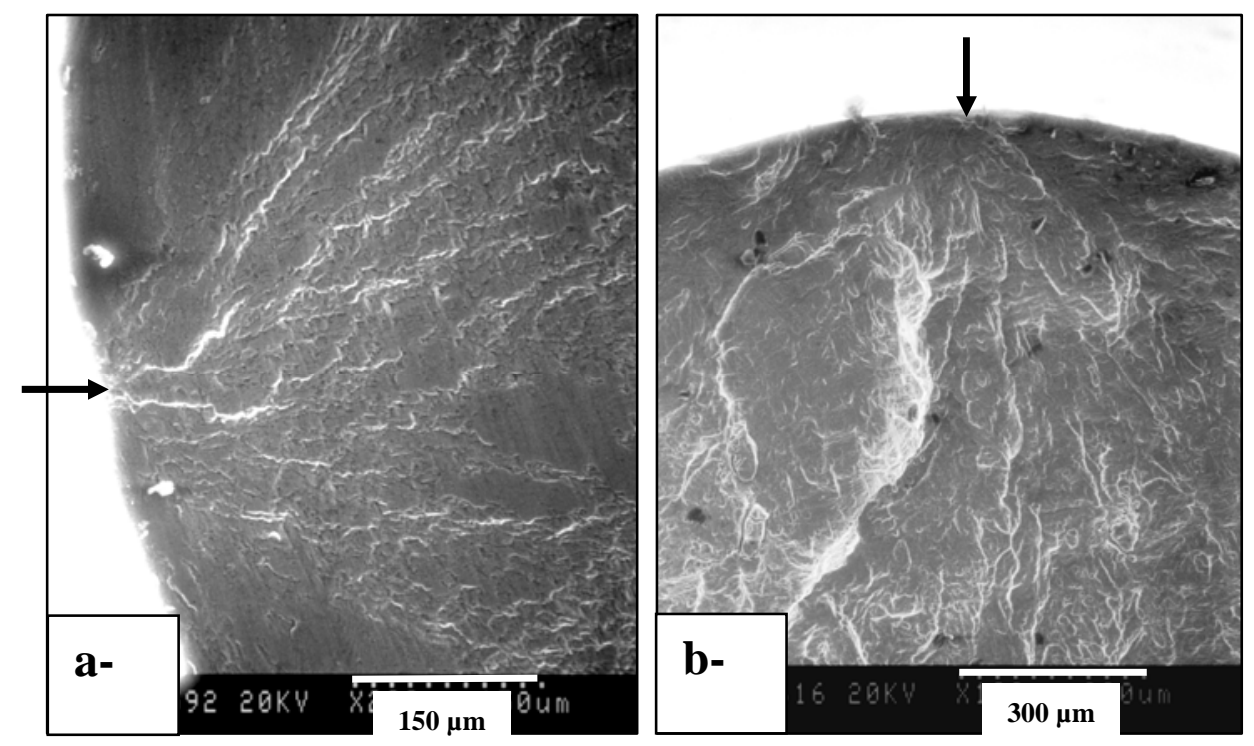

Fig. 7. Fatigue crack initiation sites on the electropolished surfaces a- Lamellar structure, b- Duplex structure
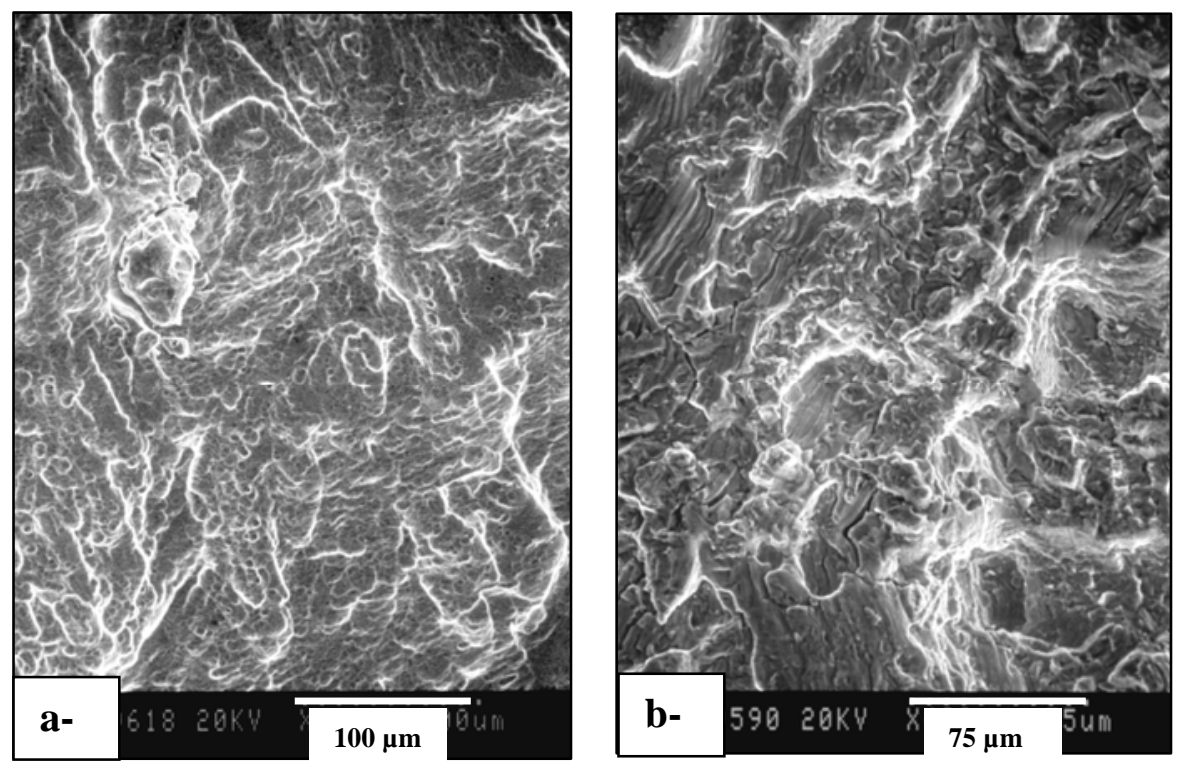

Fig. 8. Fatigue fracture surface of the investigated Ti-6.3Al-4.17V alloy a- Lamellar structure, b- Duplex structure 